\title{
Optimization of Evans blue quantitation in limited rat tissue samples
}

SUBJECT AREAS:

BLOOD-BRAIN BARRIER

BLOOD FLOW

FLUORESCENT PROBES

Received

22 July 2014

Accepted

19 September 2014

Published

10 October 2014

Correspondence and requests for materials should be addressed to T.W.L. (ted.weita@me. com)
Hwai-Lee Wang ${ }^{1} \&$ Ted Weita Lai ${ }^{1,2}$

${ }^{1}$ Graduate Institute of Clinical Medical Science, China Medical University, Taichung 404, Taiwan, ${ }^{2}$ Translational Medicine Research Center, China Medical University Hospital, Taichung 404, Taiwan.

Evans blue dye (EBD) is an inert tracer that measures plasma volume in human subjects and vascular permeability in animal models. Quantitation of EBD can be difficult when dye concentration in the sample is limited, such as when extravasated dye is measured in the blood-brain barrier (BBB) intact brain. The procedure described here used a very small volume $(30 \mu \mathrm{l})$ per sample replicate, which enabled high-throughput measurements of the EBD concentration based on a standard 96-well plate reader. First, ethanol ensured a consistent optic path length in each well and substantially enhanced the sensitivity of EBD fluorescence spectroscopy. Second, trichloroacetic acid (TCA) removed false-positive EBD measurements as a result of biological solutes and partially extracted EBD into the supernatant. Moreover, a $1: 2$ volume ratio of $50 \%$ TCA ([TCA final $]=33.3 \%$ ) optimally extracted EBD from the rat plasma protein-EBD complex in vitro and in vivo, and $1: 2$ and $1: 3$ weight-volume ratios of $50 \%$ TCA optimally extracted extravasated EBD from the rat brain and liver, respectively, in vivo. This procedure is particularly useful in the detection of EBD extravasation into the BBB-intact brain, but it can also be applied to detect dye extravasation into tissues where vascular permeability is less limiting.

vans blue dye $(\mathrm{EBD})^{1}$ is a commonly used tracer for the estimation of plasma volume in humans and the study of vascular permeability in animal models. Similar to other dyes used in human diagnosis ${ }^{1-3}, \mathrm{EBD}$ is non-toxic and not metabolically active in mammalian circulation ${ }^{1,4}$. Because of its rapid binding to serum albumin $^{5}$ and lack of cellular uptake ${ }^{6}$, its plasma concentration remains relatively constant within the hours following intravenous injection ${ }^{4,7-12}$. Therefore, its final plasma concentration following a brief moment of circulatory distribution is used to depict the total plasma volume of test subjects, including human patients $^{4,9,10,13-15}$. In addition, its extravasation into central and peripheral organs following a more prolonged time period correlates with vascular leakage of serum albumin, and its leakage into the brain parenchyma indicates blood-brain barrier (BBB) disruption ${ }^{11,16-20}$.

EBD extraction prior to spectroscopic measurements can substantially improve the accuracy of dye quantitation. In addition to direct interference by the inherent turbidity and spectroscopic properties of lipids and proteins $^{6,8,21}$ EBD binding to these biological solutes can directly alter the spectroscopic property of the dye ${ }^{22}$. Therefore, EBD extraction is particularly crucial when the EBD concentration in a tissue sample is low compared with the concentration of biological solutes. For example, the determination of the EBD amount that is extravasated into the BBB-intact or minimally BBB-damaged brain is greatly hindered because of (1) the high content of biological solutes present in brain tissues and (2) the poor permeability of EBD across the BBB ${ }^{11,16-20}$. Trichloroacetic acid (TCA), which can compete with EBD for binding to plasma proteins ${ }^{23}$, is a reagent commonly used to extract $\mathrm{EBD}^{20,24-33}$. Despite its wide application in research, the percentage yield of EBD that can be extracted via TCA remains elusive, and no report has aimed to optimize its use.

The present study comprehensively evaluated the efficiency of the TCA method in the extraction of EBD from plasma and brain tissue in vitro and in vivo. An optimized protocol in which EBD was extracted from limited biological samples and measured with high-throughput spectroscopy based on a standard 96-well plate reader is described. The relevance of the findings to vascular permeability studies in general and BBB permeability studies in particular are discussed.

\section{Results}

Spectroscopic Readings of Standard EBD Solutions versus False-Positive Readings from Biological Solutes. The concentration range within which EBD can be accurately measured by its fluorescence spectroscopy was compared with the false-positive readings that could result from auto-fluorescence of biological samples. A 96well plate was selected for spectroscopy because of its wide commercial availability; furthermore, it provides a 

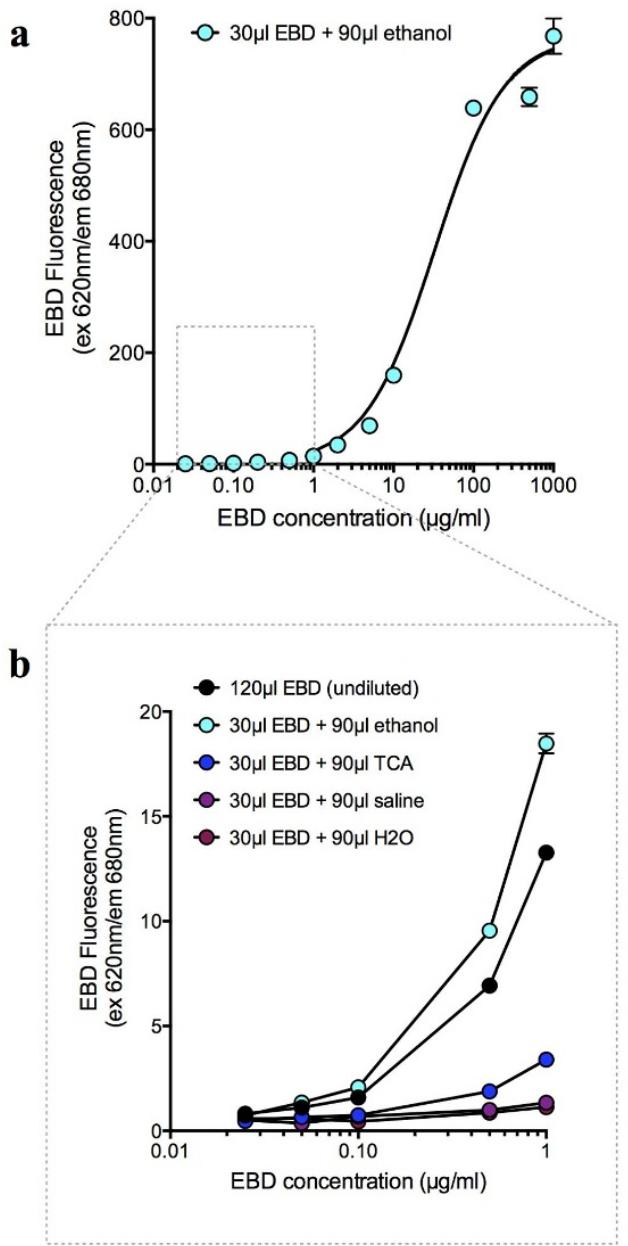

c

Clear 96-well plate

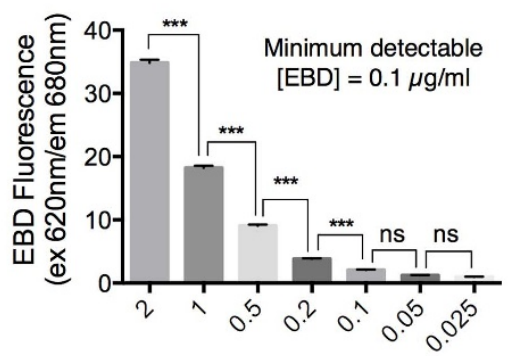

EBD concentration $(\mu \mathrm{g} / \mathrm{ml})$
Black 96-well plate

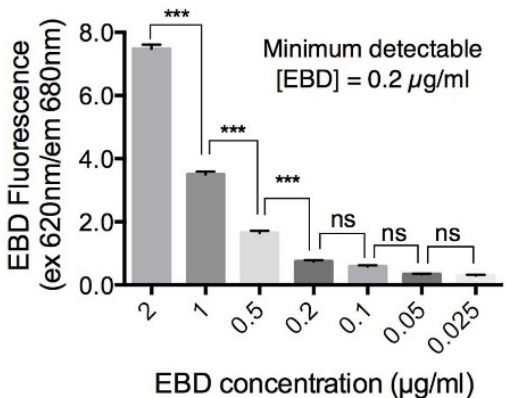

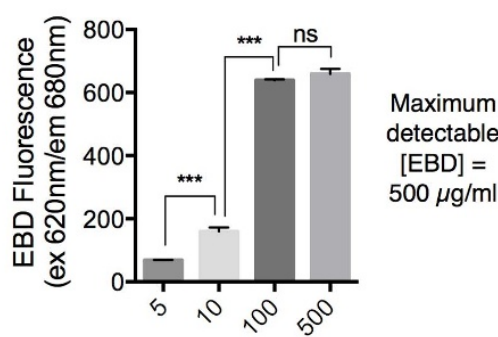

EBD concentration $(\mu \mathrm{g} / \mathrm{ml})$
Clear 96-well plate

Black 96-well plate

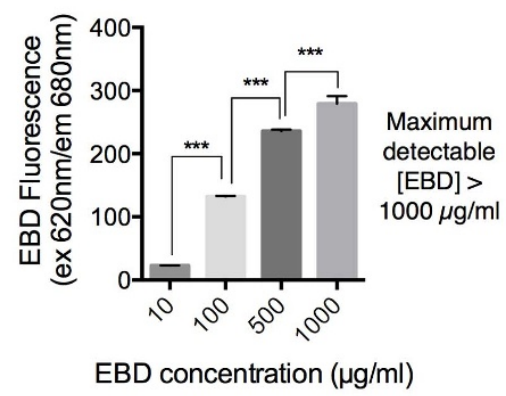

Figure $1 \mid$ Evans blue dye (EBD) fluorescence (620 $\mathrm{nm}$ excitation/680 $\mathrm{nm}$ emission) detection. Standard curve showing EBD fluorescence as a function of dye concentration in clear (a-c) and black (c) 96-well plates. (a) Full EBD standard curve based on a 1:3 ethanol dilution. Each $30 \mu 1$ replicate of EBD (in 50\% TCA/0.9\% saline) was supplemented with $90 \mu \mathrm{l}$ of $95 \%$ ethanol to ensure consistent optic path length. Concentrations of the $30 \mu \mathrm{l}$ replicates are indicated on the x-axis. (b) EBD standard curves for the $120 \mu \mathrm{l}$ undiluted dye (in 50\% TCA/0.9\% saline) and $30 \mu \mathrm{l}$ dye (in 50\% TCA/0.9\% saline) diluted to $120 \mu \mathrm{l}$ with one solvent: $95 \%$ ethanol, $50 \%$ TCA, $0.9 \%$ saline, or water. Concentrations of the $120 \mu$ l undiluted dye and the $30 \mu 1$ dye (prior to dilution) are indicated on the x-axis. (c) The maximum and minimum detectable EBD concentrations in the clear and black 96-well plates were determined by Tukey's multiple comparisons tests. A significant difference $\left({ }^{* * *} \mathrm{P}<0.001\right)$ indicates a detectable concentration difference, and no significance (ns; $\mathrm{P}>0.05)$ indicates that the concentration difference was not detectable.

reasonable optic path length even with a limited raw sample. EBD fluorescence exhibited a concentration-dependent increase from 0.1$100 \mu \mathrm{g} / \mathrm{ml}$ ( $n=12$ per group) (Fig. 1a). A step-wise comparison identified $0.1 \mu \mathrm{g} / \mathrm{ml}$ as the lowest detectable concentration with the clear 96-well plates and $0.2 \mu \mathrm{g} / \mathrm{ml}$ as the lowest detectable concentration with the black 96 -well plates ( $n=12$ per group) (Fig. 1c). Thus, the clear 96-well plate was more sensitive for the quantification of a limited sample and was used in the remainder of the study. Given the objective to minimize the samples required for accurate quantitation, we added only $30 \mu \mathrm{l}$ of EBD standard solution to each well. To ensure a consistent optic path length for each measurement, each well was subsequently filled with an additional $90 \mu \mathrm{l}$ of ethanol, TCA, saline, or water. Notably, increasing the optic path length with ethanol, compared with other solvents, substantially improved the sensitivity of fluorescence spectroscopy $(n=12$ per group; $P<0.0001$ ) (Fig. 1b). Thus, the remaining spectroscopic assays in this study used $90 \mu \mathrm{l}$ ethanol to increase the optic path length in each well of the $30 \mu$ samples.

The brain tissue extract supernatants did not appear to auto-fluoresce at $620 \mathrm{~nm} / 680 \mathrm{~nm}$ ( $n=5$ per group) (Fig. 2a); however, the plasma and blood samples strongly auto-fluoresced at $620 \mathrm{~nm} /$ $680 \mathrm{~nm}$ when $300 \mu \mathrm{l}$ were diluted to $500 \mu \mathrm{l}$ in saline $(n=5$ per group; $P<0.0001$ ) (Fig. 2b, c). Nevertheless, the precipitation of biological solutes from the plasma and blood samples via TCA removed their auto-fluorescence almost entirely $(n=5$ per group; $P<0.0001$ ) (Fig. 2b, c). When the data from Fig $2 a-c$ and la were combined, auto-fluorescence from the plasma and whole blood samples could generate up to $0.05-0.06$ and $0.2-0.3 \mu \mathrm{g} / \mathrm{ml}$ of falsepositive EBD readings, respectively, which were removed by TCAmediated precipitation.

The concentration range within which EBD can be measured from its optical density (absorbance of $620 \mathrm{~nm}$ light) and the false-positive readings that could result from the optical density of biological solutes were also compared. An EBD absorbance of $620 \mathrm{~nm}$ light exhibited a concentration-dependent increase between 1-1000 $\mu \mathrm{g} /$ $\mathrm{ml}(n=12$ per group), with an empirically determined molar extinction coefficient of $7.2 \mathrm{M}^{-1} \mathrm{~cm}^{-1}$, which is consistent with previously published values $^{34}$ (Fig. 3a, c). Therefore, in comparison with the aforementioned fluorescence readings, the absorbance readings may be more suitable for the measurement of EBD concentrations greater than $100 \mu \mathrm{g} / \mathrm{ml}$. Unlike the EBD fluorescence-concentration curve in which ethanol substantially increased the detection threshold, none of the solvents used to increase the optic path length increased the slope of the EBD concentration-absorbance standard 
a

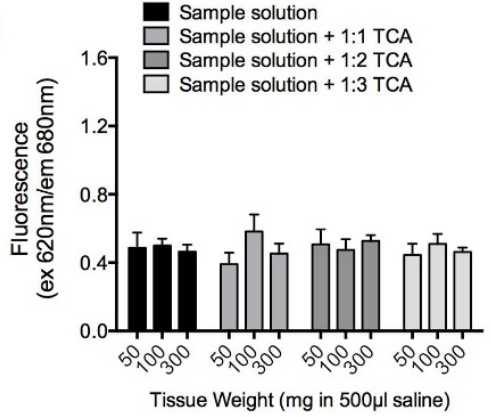

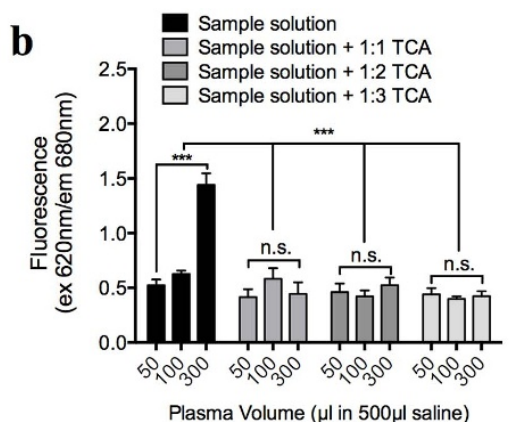

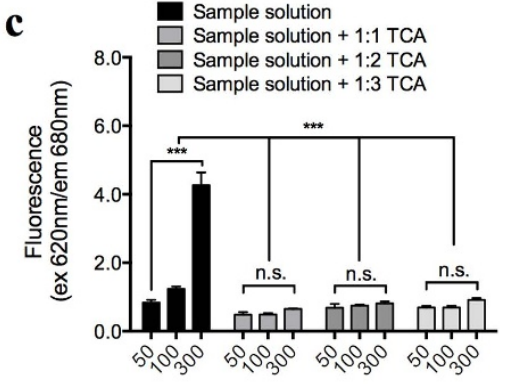

Blood Volume $(\mu \mathrm{l}$ in $500 \mu \mathrm{l}$ saline)

Figure $2 \mid$ False-positive fluorescence readings $(620 \mathrm{~nm}$ excitation/680 $\mathrm{nm}$ emission) from biological solutes. (a-c) Auto-fluorescence of biological solutes from the brain (a), blood (b), and plasma (c) samples (diluted to $500 \mu$ in saline), with or without protein-precipitation by $1: 1-1: 350 \%$ trichloroacetic acid (TCA). [TCA final following the addition of $1: 1,1: 2$, and $1: 3$ volume ratios of 50\% TCA were 25 , 33, and $37.5 \%$, respectively.
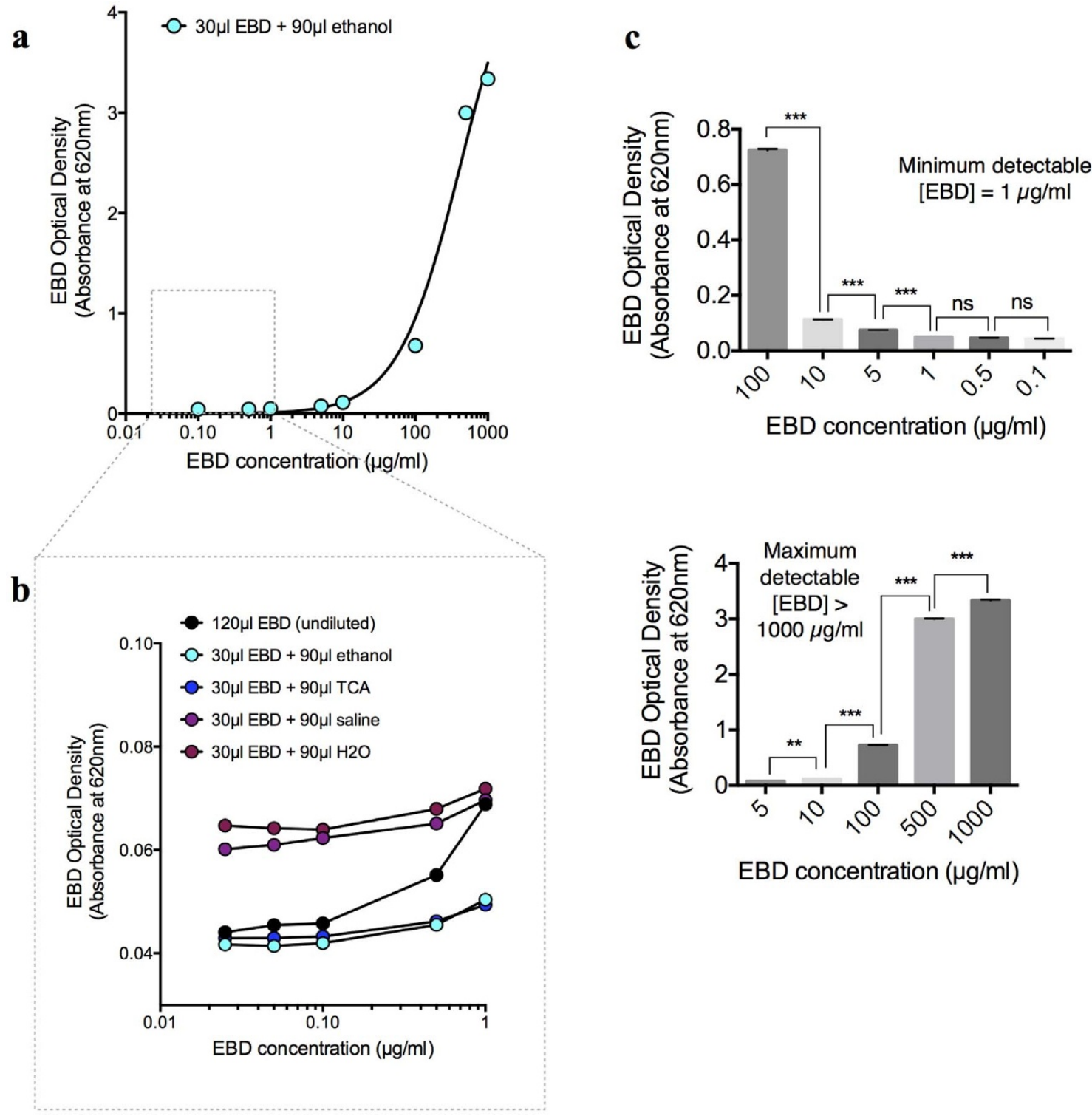

EBD concentration $(\mu \mathrm{g} / \mathrm{ml})$

Figure 3 Evans blue dye (EBD) optical density (absorbance of $620 \mathrm{~nm}$ ) detection. Standard curve showing EBD absorbance as a function of dye concentration. (a) Full EBD standard curve based on a 1:3 ethanol dilution. Each $30 \mu$ replicate of EBD (in 50\% TCA/0.9\% saline) was supplemented with $90 \mu \mathrm{l}$ of $95 \%$ ethanol to ensure consistent optic path length. Concentrations of the $30 \mu \mathrm{l}$ replicates are indicated on the X-axis. (b) EBD standard curves for the $120 \mu \mathrm{l}$ undiluted dye (in 50\% TCA/ $0.9 \%$ saline) and $30 \mu \mathrm{l}$ dye (in 50\% TCA/ $0.9 \%$ saline) diluted to $120 \mu \mathrm{l}$ with one solvent: $95 \%$ ethanol, $50 \%$ TCA, $0.9 \%$ saline, or water. Concentrations of the $120 \mu \mathrm{l}$ undiluted dye and the $30 \mu \mathrm{l}$ dye (prior to dilution) are indicated on the $\mathrm{x}$-axis. (c) The maximum and minimum detectable EBD concentrations in the clear 96-well plate were determined by Tukey's multiple comparisons tests. A significant difference $\left(* * * \mathrm{P}<0.001\right.$ and $\left.{ }^{* *} \mathrm{P}<0.01\right)$ indicates a detectable concentration difference, and no significance $(\mathrm{ns} ; \mathrm{P}>0.05)$ indicates that the concentration difference was not detectable. 

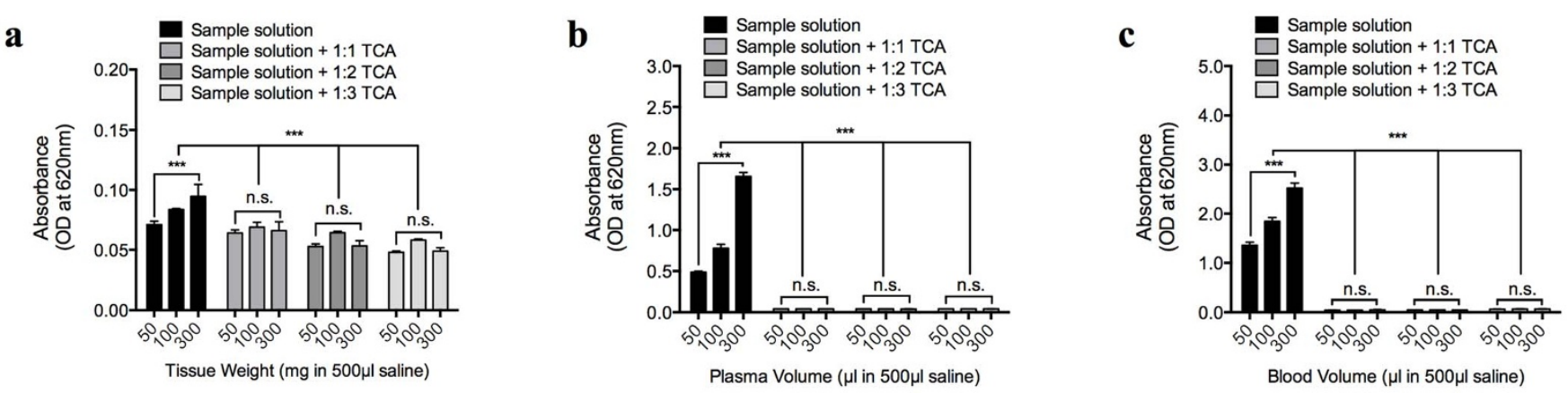

Figure 4 False-positive optical density readings (absorbance of $620 \mathrm{~nm}$ ) from biological solutes. (a-c) Absorbance of biological solutes from the brain (a), blood (b), and plasma (c) samples (diluted to $500 \mu \mathrm{l}$ in saline), with or without protein-precipitation by $1: 1-1: 3$ of $50 \%$ trichloroacetic acid (TCA). $\left[\mathrm{TCA}_{\text {final }}\right.$ following the addition of $1: 1,1: 2$, and $1: 3$ volume ratios of $50 \%$ TCA were 25,33 , and $37.5 \%$, respectively.

curve ( $n=12$ per group) (Fig. 3b). Without TCA treatment, the biological extracts ( $0.9 \%$ saline) from the brain, blood, or plasma produced strong absorbance readings at $620 \mathrm{~nm}(n=5$ per group; $P<0.0001$ ) (Fig. $4 \mathrm{a}-\mathrm{c}$ ), thereby producing up to $400-500 \mu \mathrm{g} / \mathrm{ml}$ of false-positive EBD readings. The precipitation of these solutes via TCA removed the tissue absorbance $(n=5$ per group; $P<0.0001)$ (Fig. $4 \mathrm{a}-\mathrm{c}$ ) and thereby avoided false-positive EBD readings.

Percent Yield of EBD Extracted from in vitro Protein Complex and in vivo Biological Samples with Different Volume Ratios of TCA. We investigated the percentage of EBD that can be extracted from the protein-EBD complex via TCA and the optimal volume ratio of a $50 \%$ TCA solution used to extract EBD. A protein-rich plasma solution was obtained from the arterial blood and mixed with an equal volume of $\mathrm{EBD}$ in $0.9 \%$ saline to generate the protein-EBD complex (see Fig. 5a for illustration). To extract the EBD from the newly formed protein complex, each sample was subsequently mixed with different volume ratios of 50\% TCA, and the concentration of the extracted EBD solution was measured using spectroscopy. Here, $1: 2-1: 3$ volume ratios of $50 \%$ TCA extracted only $\sim 40 \%$ of the $0.5 \mu \mathrm{g} / \mathrm{ml}$ EBD from the protein-EBD complex solution $(n=6 \mathrm{per}$ group; $P<0.05$ ), and $1: 4-1: 6$ volume ratios of $50 \%$ TCA diluted the sample too much such that EBD could not be detected ( $n=6$ per group) (Fig. 5b). In comparison, $1: 2-1: 6$ volume ratios of 50\% TCA extracted $\sim 80, \sim 90$, and $\sim 100 \%$ of the 5,50 , and $500 \mu \mathrm{g} / \mathrm{ml} \mathrm{EBD,}$ respectively, from the protein-EBD complex solutions $(n=6$ per group; $P<0.01$ ) (Fig. 5c-e).

The optimal volume ratios of TCA that extracted extravasated EBD from the brain, liver, and blood of the rats intravenously injected with the dye in vivo were determined. The blue color of EBD provides an excellent contrast to the red color of blood, and successful intravenous injection in albino laboratory animals is immediately evident by the blue coloration of densely vascularized tissues (see Fig. 6a for illustration). Consistent with the minimal extravasation of EBD into the brain parenchyma, only $\sim 1 \mu \mathrm{g} / \mathrm{g}$ (EBD/tissue weight) could be detected, and this amount was optimally extracted with $1: 2-1: 5$ volume ratios of $50 \%$ TCA $(n=4$ per group; $P<0.01)$ (Fig. $6 \mathrm{~b})$. In comparison, $\sim 50 \mu \mathrm{g} / \mathrm{g}$ could be detected in the liver parenchyma; this amount was substantially extracted with a $1: 2$ volume ratio of 50\% TCA $(n=4$ per group; $P<0.0001)$ and most optimally extracted with 1:3-1:5 volume ratios of $50 \%$ TCA ( $n=4$ per group) (Fig. 6c). EBD primarily resided in the blood, with the plasma EBD concentration up to $\sim 1300 \mu \mathrm{g} / \mathrm{ml}$ ( $n=4$ per group) (Fig. 6d). This amount was substantially extracted with a $1: 1$ volume ratio of $50 \%$ TCA and most optimally extracted with $1: 2$ or $1: 3$ volume ratios of $50 \%$ TCA $(n=4$ per group; $P<0.05)$ (Fig. $6 \mathrm{~d})$.

\section{Discussion}

The present study investigated the potential pitfalls associated with EBD detection and established an optimal procedure to extract and quantify EBD from limited biological samples. While these advancements may not be crucial when an ample sample for plasma volume determination can be obtained from human subjects ${ }^{6,35}$, these findings are essential when the raw sample is limited, such as when working with small laboratory animals or when the sample tissue has a low capacity for EBD extravasation, such as the BBB-intact brain parenchyma ${ }^{11,16-19}$. First, only a small volume of extracted sample $(30 \mu \mathrm{l})$ is needed for EBD detection. Each sample replicate, which was added into the 96 -well plate, was supplemented with a $3 \mathrm{x}$ volume of ethanol to ensure consistent optical path length. Ethanol was selected for this purpose because it substantially improved the sensitivity of EBD fluorescence spectroscopy. Second, the range within which EBD can be accurately quantified under this protocol was defined. The EBD maximally absorbs light of $620 \mathrm{~nm}$ and emits red fluorescence of $680 \mathrm{~nm}^{17,18}$; thus, its concentration in tissues and plasma can be determined by either parameter ${ }^{6,18,35}$. We have shown that EBD can be accurately determined from its fluorescence within a concentration range of $0.1-100 \mu \mathrm{g} / \mathrm{ml}$ and its absorbance within a range of $1->1000 \mu \mathrm{g} / \mathrm{ml}$. In practice, a lower sensitivity of absorbance readings is sufficient for plasma volume studies in human subjects, where a large amount of blood can be obtained per subject ${ }^{6,35}$. In rodent studies of vascular permeability, the limitation of tissue mass would necessitate the higher sensitivity of fluorescent readings.

The common assumption that TCA completely extracts EBD $(\sim 100 \%$ yield) from the albumin-complex, thereby enabling the linear quantitation of dye concentration, was based on previous extraction experiments that used impractically high concentrations of over-saturating $\mathrm{EBD}(1000 \sim 4000 \mu \mathrm{g} / \mathrm{ml})$ to generate plasma protein-EBD complexes ${ }^{32}$. However, these concentrations have never been identified in the animal brain, even following BBB disruption ${ }^{33}$. The present study reproduced these findings in which $500 \mu \mathrm{g} / \mathrm{ml}$ EBD was fully extracted from the plasma protein-EBD complex; however, it was also determined that any decrease in EBD concentration in the protein-EBD complex solution substantially decreased the percentage yield of the extraction.

In conclusion, in the previous two decades, there has been an increased interest in the use of EBD to study BBB permeability in small rodents. The TCA extraction technique has emerged as a popular technique for the extraction of EBD from the protein-EBD complex. The present study investigated the efficiency and pitfalls of this procedure and established an optimal protocol that will be of general interest to individuals who utilize EBD.

\section{Methods}

Preparation of standardized EBD solutions. Standard EBD solutions of various concentrations $(0.025-1000 \mu \mathrm{g} / \mathrm{ml})$ were prepared by dissolving dye powder (Sigma cat.\# E2129-50G) in 50\% TCA (diluted in 0.9\% saline). To generate standard curves for use with small sample volumes, each replicate contained only $30 \mu \mathrm{l}$ of standard solution in each well of a black or clear 96-well plate, which was subsequently supplemented with $90 \mu \mathrm{l}$ of solvent to provide consistent optical path length for 
$\mathbf{a}$

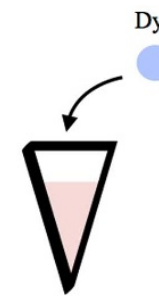

Protein-rich Plasma
Dye

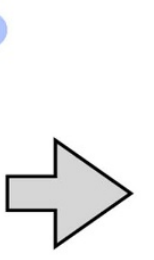

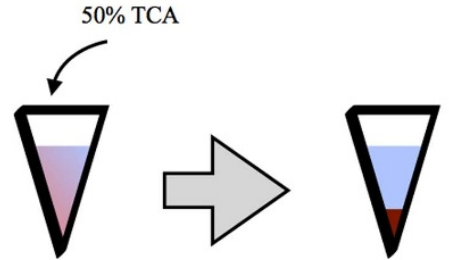

Extracted EBD in supernatant

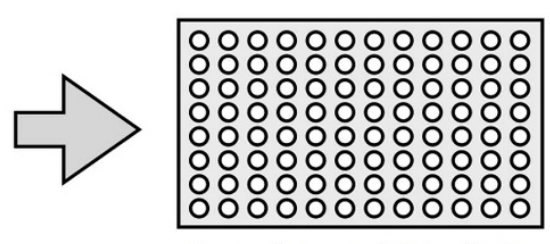

Spectrophotometry in 96-well plate

Protein-EBD complex + 1:1 TCA, 25.0\% [TCA final]

Protein-EBD complex + 1:2 TCA, 33.3\% [TCA final]

Protein-EBD complex + 1:3 TCA, 37.5\% [TCA final]

Protein-EBD complex + 1:4 TCA, 40.0\% [TCA final]

Protein-EBD complex + 1:5 TCA, 41.7\% [TCA final]

Protein-EBD complex + 1:6 TCA, 42.9\% [TCA final]

b

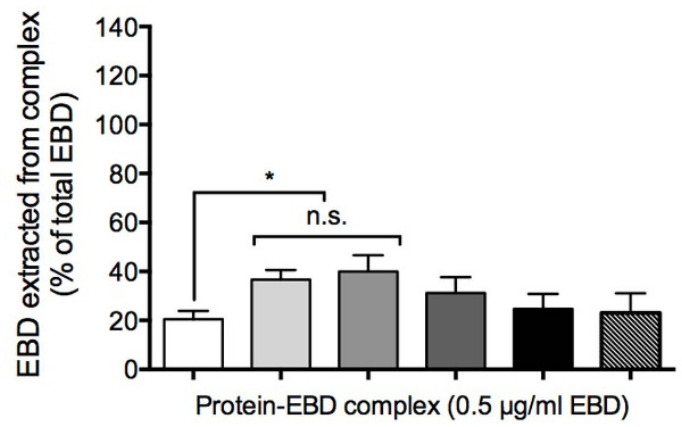

d

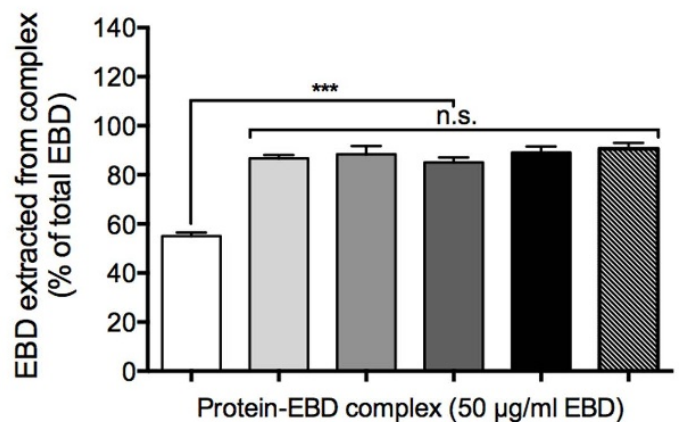

C

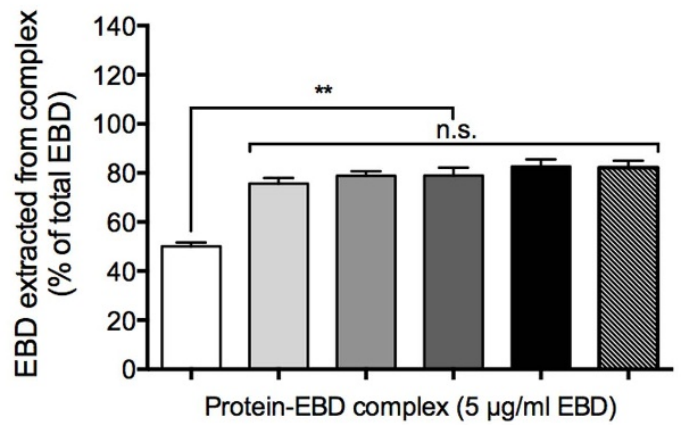

$\mathbf{e}$

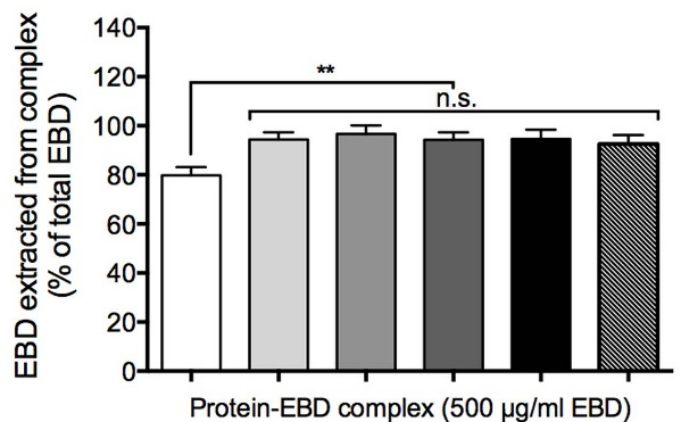

Figure 5 Extraction of Evans blue dye (EBD) from the protein-EBD complex in vitro. (a) Illustration showing the experimental protocol for (b-e). EBD formed a complex with plasma proteins. Thereafter, the dye was extracted from the protein with $50 \%$ trichloroacetic acid (TCA), and its concentration was detected by spectroscopy in a 96-well plate. (b-e) The percentage yields of EBD that were extracted from the protein-EBD complex by different volume-ratios of $50 \%$ TCA (in $0.9 \%$ saline), which resulted in different $\left[\mathrm{TCA}_{\text {final }}\right.$, were compared. The extracted EBD was measured by spectroscopy and normalized to the total EBD added to the plasma samples to generate the protein-EBD complex solutions. The total EBD concentrations were as follows: $0.5 \mu \mathrm{g} / \mathrm{ml}(\mathrm{b}), 5 \mu \mathrm{g} / \mathrm{ml}$ (c), $50 \mu \mathrm{g} / \mathrm{ml}(\mathrm{d})$, and $500 \mu \mathrm{g} / \mathrm{ml}(\mathrm{e})$.

spectroscopic measurements. For comparison, the solvent used comprised 95\% ethanol, $50 \%$ TCA (in $0.9 \%$ saline), $0.9 \%$ saline, or distilled water. A $120 \mu$ undiluted EBD standard was also included to control for the dilution by the solvent. Each well was thoroughly mixed by repetitive pipetting, and the spectroscopic detection of (1) absorbance at $620 \mathrm{~nm}$ and (2) fluorescence by $620 \mathrm{~nm}$ excitation and $680 \mathrm{~nm}$ emission was conducted using a standard plate reader (SpectraMax ${ }^{\circledR}$ M2e). The maximum and minimum detectable concentrations were determined by a Tukey's multiple comparisons test and are indicated by a significant difference in the spectroscopic readings between each incremental increase in concentration (Fig. 1c). Thus, the minimum detectable concentrations for EBD fluorescence were 0.1 and $0.2 \mu \mathrm{g} / \mathrm{ml}$ for the clear and black 96-well plates, respectively. The maximum concentrations were 500 and $>1000 \mu \mathrm{g} / \mathrm{ml}$ for the clear and black 96-well plates, respectively. The minimum concentration for absorbance detection was $1 \mu \mathrm{g} / \mathrm{ml}$, and the maximum concentration was $>1000 \mu \mathrm{g} / \mathrm{ml}$.
Biological solutes from brain, blood, and plasma. Three rats were used in these in vitro experiments. Each rat was euthanized by an overdose of urethane anesthesia, and its right femoral artery was cannulated to facilitate arterial blood collection. The blood samples were maintained on ice to slow coagulation (as no anti-coagulant was used during blood collection) and were centrifuged at $10,000 \times g$ (for $20 \mathrm{~min}$ ) to obtain a cell-free plasma sample. Prior to brain tissue isolation, each rat was thoroughly perfused with $0.9 \%$ saline to rid the brain of circulating blood. The isolated brain parenchyma was cut and weighed into small pieces $(50,100$, and $300 \mathrm{mg}$ ) and incubated in $500 \mu \mathrm{l}$ of $0.9 \%$ saline for at least $60 \mathrm{~min}$ to enable the soluble biomolecules to dissolve. The solutions were centrifuged at $10,000 \times g$ for $10 \mathrm{~min}$ to sediment the non-dissolved tissue parts, and the supernatants that contained the brain solutes received no further treatment or were treated with $1: 1$, $1: 2$, or $1: 3$ volume-ratios of $50 \%$ TCA, which resulted in a $\left[\mathrm{TCA}_{\text {final }}\right]$ of $25.0,33.3$, and $37.5 \%$, respectively. The blood and plasma samples $(50,100,300 \mu \mathrm{l})$ were each 
$\mathbf{a}$
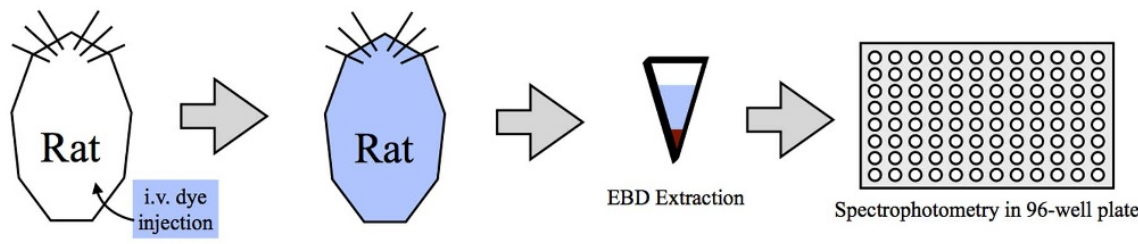

b
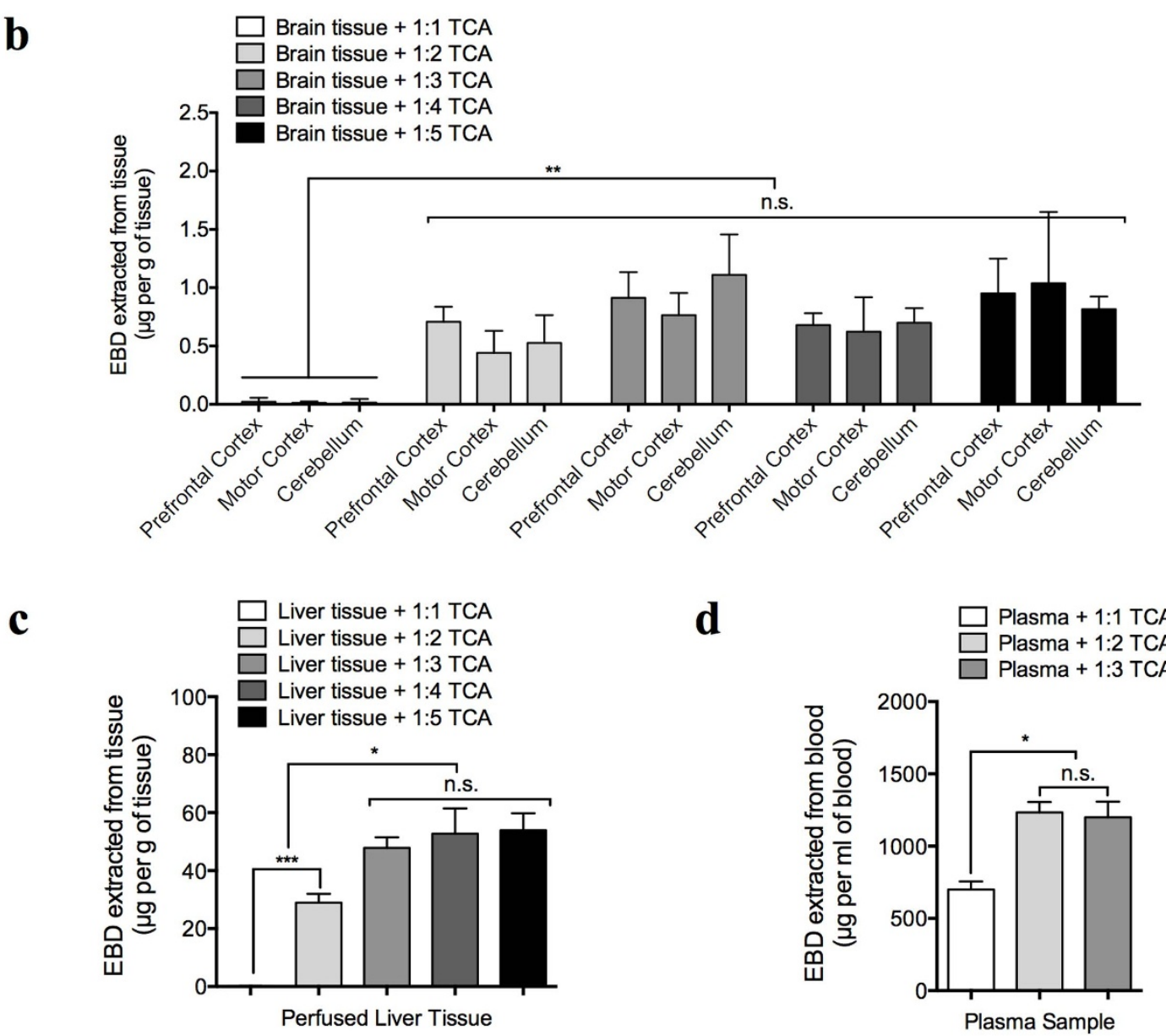

Figure 6 Extraction of Evans blue dye (EBD) from the protein-EBD complex and peripheral/central organs in vivo. (a) Illustration showing the experimental protocol for (b-d). Each rat was injected with EBD; EBD was extracted from the central/peripheral organs 2 h later, and its concentration was measured by spectroscopy in a 96-well plate. (b-d) EBD was extracted by different volume-ratios of 50\% TCA (in $0.9 \%$ saline) from the brain parenchyma (b), liver parenchyma (c), and plasma (d) in rats injected with the dye $2 \mathrm{~h}$ prior to sample collection.

diluted with $0.9 \%$ saline to a final volume of $500 \mu \mathrm{l}$ and received no further treatment or were treated with $1: 1,1: 2$, or $1: 3$ volume-ratios of $50 \%$ TCA, which resulted in a $\left[\mathrm{TCA}_{\text {final }}\right]$ of $25.0,33.3$, and $37.5 \%$, respectively. To prevent blood coagulation, the blood samples were treated with $0.25 \mathrm{U}$ heparin $(10 \mu \mathrm{l}$ of $25 \mathrm{U}$ heparin into a $1000 \mu \mathrm{l}$ blood sample) immediately prior to dilution with $0.9 \%$ saline. Following TCA treatment, the brain, blood, and plasma samples were further centrifuged at 10,000 $\times$ $g$ for $20 \mathrm{~min}$ to remove precipitated biomolecules. The final supernatant, with or without the TCA extraction procedure, was added to a clear 96-well plate $(30 \mu \mathrm{l}$ per well). Following the supplementation of each well with $90 \mu \mathrm{l}$ of $95 \%$ ethanol to increase its optic path length, each well was thoroughly mixed by repetitive pipetting, and its absorbance $(620 \mathrm{~nm})$ and fluorescence $(620 \mathrm{~nm} / 680 \mathrm{~nm})$ were determined.

Preparation and extraction of the plasma protein-EBD complex. The plasma samples, which were collected as previously described, were mixed with equal volumes of EBD solutions $(1,10,100$, or $1000 \mu \mathrm{g} / \mathrm{ml}$ in $0.9 \%$ saline). Following at least $10 \mathrm{~min}$ to enable adequate plasma protein-EBD complex formation and with final EBD concentrations of $0.5,5,50$, or $500 \mu \mathrm{g} / \mathrm{ml}$, each sample was treated with different volume-ratios of $50 \%$ TCA $\left(1: 1-1: 6\right.$, which resulted in a $\left[\mathrm{TCA}_{\text {final }}\right]$ of $25.0,33.3$, $37.5,40.0,41.7$, and $42.9 \%$, respectively). The TCA-treated solutions were further centrifuged at 10,000 $\times g$ for $20 \mathrm{~min}$ to remove the precipitated plasma proteins and lipids, and the extracted supernatants were added to a clear 96-well plate $(30 \mu \mathrm{l}$ per well, supplemented with $90 \mu \mathrm{l}$ of $95 \%$ ethanol and mixed thoroughly by pipetting) for the spectroscopic assay. Based on our standard curves in Fig. 1A and 3A, the concentrations of the extracted EBD from the 0.5 and $5 \mu \mathrm{g} / \mathrm{ml}$ samples could be accurately determined from their fluorescence $(620 \mathrm{~nm} / 680 \mathrm{~nm})$ readings, and the concentrations from the 50 and $500 \mu \mathrm{g} / \mathrm{ml}$ samples could be determined from their absorbance $(620 \mathrm{~nm})$ readings.

Calculation of extraction efficiency. The extraction efficiency was determined from the ratio of the extracted $\mathrm{EBD}$ concentration ( $\left[\mathrm{EBD}_{\text {extracted }}\right]$ in $\mu \mathrm{g} / \mathrm{ml}$ ) to the initial EBD concentration ( $\left[\mathrm{EBD}_{\text {initial }}\right]$ of $0.5,5,50$, or $\left.500 \mu \mathrm{g} / \mathrm{ml}\right)$. The $\left[\mathrm{EBD}_{\text {extracted }}\right]$ was calculated by multiplying the measured EBD concentration, based on the standard curves derived from the spectroscopic readings, by the respective dilution factors that resulted from TCA treatment. Thus, the extraction efficiency was $100 \%$ when the $\left[\mathrm{EBD}_{\text {extracted }}\right]$ was equal to the $\left[\mathrm{EBD}_{\text {initial }}\right]$, and the extraction was only partial when the $\left[\mathrm{EBD}_{\text {extracted }}\right]$ was less than the $\left[\mathrm{EBD}_{\text {initial }}\right]$.

In vivo EBD injection and dye extraction. Eight rats were used for the in vivo experiments, which were performed under deep urethane anesthesia (4 g/kg, i.p.). Each rat was placed on a heating pad to maintain body temperature throughout the 
experiment. The right femoral vein and artery were cannulated. EBD, which was prepared as a $4 \%$ solution in $0.9 \%$ saline, was injected as a single bolus dose of $2 \mathrm{ml} / \mathrm{kg}$ via the venous cannula. After a $120 \mathrm{~min}$ period to enable uniform blood distribution, the EBD-stained blood was collected from the arterial cannula. The blood samples were placed on ice until centrifugation at $10,000 \times g$ to sediment blood cells, and the EBD-stained plasma supernatants were collected in separate tubes. EBD extraction from plasma was accomplished via the addition of 50\% TCA at $1: 1-1: 3$ volumeratios, which resulted in a $\left[\mathrm{TCA}_{\text {final }}\right]$ of $25.0,33.3$, and $37.5 \%$, respectively. Immediately following blood collection, each rat was thoroughly perfused with $0.9 \%$ saline to rid the circulation of remaining dye, and the perfused brain and liver tissues were collected. For extraction, the brain and liver tissues were placed in 1:1-1:5 weight $(\mathrm{mg})$ :volume $(\mu \mathrm{l})$ ratios of $50 \% \mathrm{TCA}$, and they were homogenized for $5 \mathrm{~min}$ (continuous beating) using a metal-bead homogenizer (BULLET BLENDER ${ }^{\circledR}$ BBX24). The TCA/extracts from the plasma, brain, and liver samples were centrifuged at $10,000 \times g$ for $20 \mathrm{~min}$ to remove precipitates, tissue debris, and metal beads, and the supernatants were added to a 96 -well plate $(30 \mu \mathrm{l}$ per well, each plate supplemented with $90 \mu \mathrm{l}$ of $95 \%$ ethanol and thoroughly mixed by pipetting) for fluorescence spectroscopy $(620 \mathrm{~nm} / 680 \mathrm{~nm})$.

Animal care. The procedures that involved experimental animals were conducted in accordance with the Institutional Guidelines of China Medical University for the Care and Use of Experimental Animals (IGCMU-CUEA) and were approved by the Institutional Animal Care and Use Committee (IACUC) of China Medical University (Taichung, Taiwan) (Protocol No. 101-274-N). Male Sprague-Dawley rats (260$450 \mathrm{~g}$ ) were used in this study. The rats had free access to rat chow and water ad libitum prior to use in the experiments.

Data presentation and statistical analysis. The data are presented as the mean \pm SEM. The extraction efficiencies by different volume-ratios of TCA were compared by 1-WAY or 2-WAY repeated measures ANOVA, in which the plasma samples and tissues from the same animals were matched. Each ANOVA test was followed by a Tukey's multiple comparisons test to determine the differences between specific groups.

1. Evans, H. M. \& Schulemann, W. The Action of Vital Stains Belonging to the Benzidine Group. Science 39, 443-454, doi:10.1126/science.39.1004.443 (1914).

2. Keith, N. M., Rowntree, L. G. \& Geraghty, J. T. A method for the determination of plasma and blood volume. Arch Intern Med (Chic) XVI, 547-576 (1915).

3. Robertson, O. H. \& Bock, A. V. Blood Volume in Wounded Soldiers : I. Blood Volume and Related Blood Changes after Hemorrhage. J Exp Med 29, 139-153 (1919).

4. Dawson, A. B., Evans, H. M. \& Whipple, G. H. BLOOD VOLUME STUDIES III. Behavior of Large Series of Dyes Introduced into the Circulating Blood. Am J Physiol 51, 232-256 (1920).

5. Rawson, R. A. The binding of T-1824 and structurally related diazo dyes by the plasma proteins. Am J Physiol 138, 708-717 (1943).

6. Gregersen, M. I., Gibson, J. J. \& Stead, E. A. Plasma volume determination with dyes: errors in colorimetry; use of the blue dye T-1824. Am J Physiol 113, 54-55 (1935).

7. Yen, L. F., Wei, V. C., Kuo, E. Y. \& Lai, T. W. Distinct patterns of cerebral extravasation by evans blue and sodium fluorescein in rats. PLoS One 8, e68595, doi:10.1371/journal.pone.0068595 (2013).

8. Crooke, A. C. \& Morris, C. J. The determination of plasma volume by the Evans blue method. J Physiol 101, 217-223 (1942).

9. Bowler, R. G., Crooke, A. C. \& Morris, C. J. The effect of morphine and hyoscine on dye concentration curves in plasma volume determination. J Physiol 103 137-141 (1944).

10. Crooke, A. C., Morris, C. J. \& Bowler, R. G. General Anaesthesia in Shock. Br Med J 2, 683-686 (1944)

11. Gregersen, M. I. \& Rawson, R. A. The disappearance of T-1824 and structurally related dyes from the blood stream. Am J Physiol 138, 698-707 (1943).

12. Rossner, W. \& Tempel, K. [Quantitative determination of the permeability of the so-called blood-brain barrier of Evans blue (T 1824)]. Med Pharmacol Exp Int J Exp Med 14, 169-182 (1966).

13. Theron, P. H. \& Wilson, W. C. Blood changes in peritonitis. Lancet 1, 172-178 (1949).

14. Dacie, J. V. \& Homer, G. F. Blood-loss in battle casualties; use of transfusion fluids. Lancet 1, 371-377 (1946)

15. Crooke, A. C., Morris, C. J. \& Bowler, R. G. Plasma Volume in Traumatic Shock. Br Med J 2, 521-522 (1944).

16. Sutherland, T. M. \& Young, D. A. Increased permeability of the capillaries of the rat heart to plasma albumin with asphyxiation and with perfusion. J Physiol $\mathbf{1 8 3}$ 112-122 (1966).

17. Steinwall, O. \& Klatzo, I. Selective vulnerability of the blood-brain barrier in chemically induced lesions. J Neuropathol Exp Neurol 25, 542-559 (1966).

18. Saria, A. \& Lundberg, J. M. Evans blue fluorescence: quantitative and morphological evaluation of vascular permeability in animal tissues. J Neurosci Methods 8, 41-49 (1983)
19. Clasen, R. A., Pandolfi, S. \& Hass, G. M. Vital staining, serum albumin and the blood-brain barrier. J Neuropathol Exp Neurol 29, 266-284 (1970).

20. Chen, K. B. et al. Increase in Evans blue dye extravasation into the brain in the late developmental stage. Neuroreport 23, 699-701, doi:10.1097/ WNR.0b013e3283556dcc (2012).

21. Morris, C. J. The determination of plasma volume by the Evans blue method: the analysis of haemolysed plasma. J Physiol 102, 441-445 (1944).

22. Allen, T. H., Ochoa, M., Roth, R. F. \& Gregersen, M. I. Spectral absorption of T 1824 in plasma of various species and recovery of the dye by extraction. Am J Physiol 175, 243-246 (1953).

23. Grimbleby, F. H. \& Ntailianas, H. A. Binding of trichloroacetic acid by protein. Nature 189, 835-836 (1961).

24. Ay, I., Francis, J. W. \& Brown, R. H., Jr. VEGF increases blood-brain barrier permeability to Evans blue dye and tetanus toxin fragment $\mathrm{C}$ but not adenoassociated virus in ALS mice. Brain Res 1234, 198-205, doi:10.1016/ j.brainres.2008.07.121 (2008).

25. Belayev, L., Busto, R., Zhao, W. \& Ginsberg, M. D. Quantitative evaluation of blood-brain barrier permeability following middle cerebral artery occlusion in rats. Brain Res 739, 88-96 (1996)

26. Wang, Z., Leng, Y., Tsai, L. K., Leeds, P. \& Chuang, D. M. Valproic acid attenuates blood-brain barrier disruption in a rat model of transient focal cerebral ischemia: the roles of HDAC and MMP-9 inhibition. J Cereb Blood Flow Metab 31, 52-57, doi:10.1038/jcbfm.2010.195 (2011).

27. Altay, O. et al. Isoflurane attenuates blood-brain barrier disruption in ipsilateral hemisphere after subarachnoid hemorrhage in mice. Stroke 43, 2513-2516, doi:10.1161/STROKEAHA.112.661728 (2012).

28. Jackman, K. et al. Progranulin deficiency promotes post-ischemic blood-brain barrier disruption. J Neurosci 33, 19579-19589, doi:10.1523/JNEUROSCI.4318 13.2013 (2013).

29. Yan, J., Zhou, B., Taheri, S. \& Shi, H. Differential effects of HIF-1 inhibition by YC 1 on the overall outcome and blood-brain barrier damage in a rat model of ischemic stroke. PLoS One 6, e27798, doi:10.1371/journal.pone.0027798 (2011).

30. Lee, J. Y., Kim, H. S., Choi, H. Y., Oh, T. H. \& Yune, T. Y. Fluoxetine inhibits matrix metalloprotease activation and prevents disruption of blood-spinal cord barrier after spinal cord injury. Brain 135, 2375-2389, doi:10.1093/brain/aws171 (2012).

31. Hasegawa, Y., Suzuki, H., Altay, O., Chen, H. \& Zhang, J. H. Treatment with sodium orthovanadate reduces blood-brain barrier disruption via phosphatase and tensin homolog deleted on chromosome 10 (PTEN) phosphorylation in experimental subarachnoid hemorrhage. JNeurosci Res 90, 691-697, doi:10.1002/ jnr.22801 (2012).

32. Uyama, O. et al. Quantitative evaluation of vascular permeability in the gerbil brain after transient ischemia using Evans blue fluorescence. J Cereb Blood Flow Metab 8, 282-284, doi:10.1038/jcbfm.1988.59 (1988).

33. Chen, K. B. et al. Intravenous mannitol does not increase blood-brain barrier permeability to inert dyes in the adult rat forebrain. Neuroreport 24, 303-307, doi:10.1097/WNR.0b013e32835f8acb (2013).

34. Roberts, W. G. \& Palade, G. E. Increased microvascular permeability and endothelial fenestration induced by vascular endothelial growth factor. J Cell Sci 108 (Pt 6), 2369-2379 (1995).

35. Lawrence, A. C. \& Walters, G. The extraction of Evans blue (T1824) from plasma and the measurement of plasma volume. J Clin Pathol 12, 123-127 (1959).

\section{Acknowledgments}

This work was supported by research grants from China Medical University Hospital (DMR-102-125), the Taiwan Ministry of Health and Welfare Clinical Trial and Research Center of Excellence (MOHW103-TDU-B-212-113002), and the Taiwan Ministry of Science and Technology (MOST102-2321-B-039-008).

\section{Author contributions}

H.L.W. and T.W.L. conceived the study and analyzed the data. H.L.W. performed the experiments. T.W.L. wrote the manuscript. Both authors reviewed and edited the manuscript.

\section{Additional information}

Competing financial interests: The authors declare no competing financial interests.

How to cite this article: Wang, H.-L. \& Lai, T.W. Optimization of Evans blue quantitation in limited rat tissue samples. Sci. Rep. 4, 6588; DOI:10.1038/srep06588 (2014).

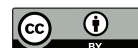

This work is licensed under a Creative Commons Attribution 4.0 International License. The images or other third party material in this article are included in the article's Creative Commons license, unless indicated otherwise in the credit line; if the material is not included under the Creative Commons license, users will need to obtain permission from the license holder in order to reproduce the material. To view a copy of this license, visit http://creativecommons.org/licenses/by/4.0/ 